\title{
Quality-Detection for Boom Cylinder Remanufactured Products
}

\author{
Pin-pin Qin ${ }^{1, a^{*}}$, Qi Hong ${ }^{2, b}$, Cui-ce Chen ${ }^{3, \mathrm{c}}, \mathrm{Xin} \mathrm{Li}^{4, \mathrm{~d}}$ and Shi-Kang Pei ${ }^{5, \mathrm{e}}$ \\ 1,3,4,5 College of Mechanical Engineering, Guangxi University, Nanning, Guangxi, China \\ ${ }^{2}$ Remanufacturing Company, Guangxi Liu Gong Machinery Co., Ltd, Liuzhou, Guangxi, China

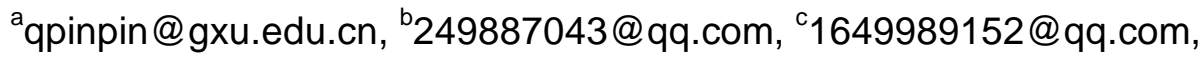 \\ d1045375763@qq.com, e2271727585@qq.com \\ * please mark the corresponding author with an asterisk
}

Keywords: Remanufacturing; Quality-Detection; Boom Cylinder; Wheel Loader.

Abstract. In order to guarantee the quality, functionalities and characteristics of remanufactured products, the quality-detection is obligatory and important. A research on quality-detection for boom cylinder remanufactured products is accomplished in this paper. Remanufacturing technological requirements of boom cylinder is introduced. Methods and standards of quality-detection for boom cylinder remanufactured products are built. A set of remanufactured boom cylinder is chosen randomly and tested on special equipment made by enterprise independently. The testing results show that this remanufactured products are qualified for all testing metrics. Tests and application results show that the remanufactured products performs similarly to a new one, with the same quality, functionalities and characteristics. With this warranty that remanufactured products can really meet the client's needs. It is feasible that methods and standards of quality-detection we proposed in this paper for remanufactured boom cylinder.

\section{Introduction}

Worldwide, remanufacturing is becoming more prevalent; not only do firms wish to maximize profits from product returns, but both societal and governmental pressures to enhance resource conservation motivate firms to adopt remanufacturing [1]. A remanufactured products is one that has gone through "the process of disassembling, cleaning, inspecting, repairing, replacing, and reassembling the components of apart or product to like-new condition" [2-3].Because products are restored to a like-new condition, remanufacturing is characteristically distinct from repair, refurbishment, or reuse activities [4].

How can we give the result that remanufactured products to like-new condition or even surpass the new ones? Or how should remanufactured products come with a guarantee that they meet the client's needs just like a new product? How to ensure the quality of the product and evaluate it becomes the key to promote the remanufacturing engineering [5].The quality-detection for remanufactured products is the key. A final quality-detection will ensure that the remanufactured products perform similarly to a new one, with the same characteristics, functionalities and quality [6].

A large number of failure cylinder is eliminated and abandoned in the construction machinery industry, if it can be remanufactured, then it can be achieved resource reuse [7]. Remanufacturing will earn numerous benefits for the original equipment manufacturers (OEMs) [8-9].In China, there are 130,000 population of wheel loaders according to statistics at present [10]. Cylinder is the core part for construction machinery remanufacture [11]. Although remanufacturing is a large industry and is becoming a well-researched area, few experimental research studies specifically address the topic of quality-detection for remanufactured products; thus, researchers and enterprises are left without a developed body of research to draw upon. Our study contributes to the development of this stream of research.

In this study, we finished quality-detection of boom cylinder for remanufactured products on ZL 50C wheel loader. We began with a brief review of introduction pertaining to the background of remanufactured products. Next, we proposed methods and stands of quality-detection for boom 
cylinder remanufactured products. Finally, we carried on a test, which testing sampling, experimental results and theoretical and practical implications were discussed.

\section{Methods and Standards of Quality-Detection Test}

Testing Conditions and Technical Parameters. The quality-detection test of boom cylinder is carried on by using the hydraulic cylinder test equipment which is developed independently by the enterprise. The diagram of the test equipment is shown in figure 1.

In the experiment, the No. 46 anti-wear hydraulic oil is adopted; oil cleanliness is no higher than standard grade 9 NAS1638 and oil temperature is $50^{\circ} \mathrm{C} \pm 5^{\circ} \mathrm{C}$. Noise should be controlled below $80 \mathrm{db}$ during the operating.

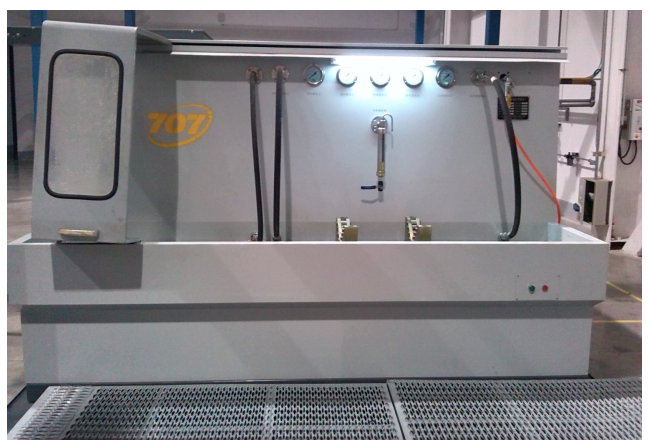

Figure 1. Test equipment for quality-detection

Testing steps and methods. Testing steps are the followings: Step1: Debugging prepare. Step 2: Characteristic test of starting pressure. Step 3: Puncture test (external leakage situation is observed at the same time). Step 4: Internal leakage test. Step 5: Travel detection. Methods and standards for each step are shown in Table 1.

Table 1. Methods and standards of quality-detection test for boom cylinder.

\begin{tabular}{|l|l|l|}
\hline \multicolumn{1}{|c|}{ Items } & \multicolumn{1}{|c|}{ Methods } & \multicolumn{1}{c|}{ Standards } \\
\hline $\begin{array}{l}\text { 1. Debugging preparation. } \\
\text { (requirement ) }\end{array}$ & $\begin{array}{l}\text { Adjust the system pressure, the hydraulic cylinder starts } \\
\text { under no load condition and moves back and forth 5 times } \\
\text { covering the whole stoke in order to expel out air in cylinder. }\end{array}$ & Movement of piston rod is flexible. \\
\hline $\begin{array}{l}\text { 2. Test of starting pressure } \\
\text { characteristics. ( } \\
\text { requirement ) }\end{array}$ & $\begin{array}{l}\text { After debugging preparation, adjust the overflow valve } \\
\text { under no load condition, pressure with rod is increasing } \\
\text { gradually until the hydraulic cylinder starts, pressure at the } \\
\text { moment is starting pressure. }\end{array}$ & Starting pressure is 0.7 MPa. \\
\hline 3. Puncture test. ( & $\begin{array}{l}\text { When 1.5 times nominal pressure oil is put into working } \\
\text { cavity, examine whether there is oil leak on the binding } \\
\text { surfaces of hydraulic cylinder. }\end{array}$ & $\begin{array}{l}\text { Input oil pressure is 21.3MPa. No } \\
\text { leakage on all binding surfaces. }\end{array}$ \\
\hline requirement ) & $\begin{array}{l}\text { When nominal pressure oil is put into working cavity, } \\
\text { leaking from piston to no pressure cavity is measured. } \\
\text { Testing method is differential pressure method, reserved } \\
\text { measuring cup method is an alternative. Read data directly } \\
\text { by differential pressure method. Measuring cup method } \\
\text { can't output data directly, which is only determined by } \\
\text { observers. }\end{array}$ & $\begin{array}{l}\text { The velocity of leakage is } 2.24 \\
\text { ml/min by differential pressure } \\
\text { method without rod, 2.24 ml/min by } \\
\text { differential pressure method with } \\
\text { rod and 2.24 ml/min by measuring } \\
\text { cup method. }\end{array}$ \\
\hline 5. External leakage test. ( & $\begin{array}{l}\text { Examine whether there is oil leakage on piston rod seals, } \\
\text { cylinder head welding, cylinder head and oil port plane. }\end{array}$ & $\begin{array}{l}\text { Good sealing performance, no leak } \\
\text { on each binding surfaces. }\end{array}$ \\
\hline $\begin{array}{l}\text { requirement ) } \\
\text { detection. ( random ) }\end{array}$ & $\begin{array}{l}\text { When hydraulic cylinder piston stops at each end of the } \\
\text { extreme position, the stroke length is measured manually. }\end{array}$ & $\begin{array}{l}\text { The scope of maximum stroke is } \\
757 ~ 763 m m . ~\end{array}$ \\
\hline
\end{tabular}

\section{Test}

Testing sample. Boom cylinder is an important part of engineering machinery, which is the final step to convert hydraulic power into concrete action. It plays a key role in the hydraulic transmission 
system, its performance directly determines the performance of the whole hydraulic transmission system and its reliability level. Its typical failure mode is internal leakage which caused by scratches on the cylinder wall [12]. Internal leakage will reduce the output power of the hydraulic cylinder.

Repair size method is widely applied by foreign remanufacturing enterprises [13]. After using repair size method to repair the boom cylinder, reassembling is made. Due to the size changes in repaired boom cylinder, in order to ensure the fitting accuracy, the selected piston must be corresponded to the new repaired size. Before reassembling, it is essential to ensure all parts clean. The outer surface, bore and oil path of all parts need to be washed and dry. Firstly, there are piston packages assembling, cylinder head packages and piston rod packages, then the main cylinder assembling. Testing sample is chosen randomly among the remanufactured valves, which can guarantee consistency of remanufacturing technology and reassembling.

Testing results. The quality-detection of sample is tested according to the methods provided in the prior section and the testing results are shown in table 2.

Table 2 shows that all the quality-detection metrics of boom cylinder for remanufactured products are qualified, which will ensure the remanufactured products performs similarly to a new one, with the same quality, functionalities and characteristics.

At the same time, the department of after-sale service in remanufacturing company made investigations for remanufactured products by sending questionnaires to clients. Clients who has bought this kind of remanufactured products, such as boom cylinder, gave the evaluation that they can't find the difference between the remanufactured products and new ones in functionalities. The price of remanufactured products is much lower than new ones. Clients are more pleased with remanufactured products which are guaranteed qualified.

Table 2. Results of quality-detection test for boom cylinder

\begin{tabular}{|l|l|c|}
\hline \multicolumn{1}{|c|}{ Items } & \multicolumn{1}{|c|}{ Testing results } & Conclusion \\
\hline 1. Debugging preparation. & $\begin{array}{l}\text { Movement of piston rod is flexible. No leakage on all binding } \\
\text { surfaces. }\end{array}$ & Qualified \\
\hline 2. Test of starting pressure characteristics. & Starting pressure is $0.28 \mathrm{MPa}$. & Qualified \\
\hline 3. Puncture test. & No oil leakage on the cylinder combination surface. & Qualified \\
\hline $\begin{array}{l}\text { 4. Internal leakage test. } \\
\text { Differential pressure method without rod. }\end{array}$ & The velocity of leakage is $1.81 \mathrm{ml} / \mathrm{min}$. & Qualified \\
\hline $\begin{array}{l}\text { 5. Internal leakage test. } \\
\text { Differential pressure method without rod. }\end{array}$ & The velocity of leakage is $1.81 \mathrm{ml} / \mathrm{min}$. & Qualified \\
\hline $\begin{array}{l}\text { 6. Internal leakage test. } \\
\text { Differential pressure method without rod. }\end{array}$ & The velocity of leakage is $1.18 \mathrm{ml} / \mathrm{min}$. & Qualified \\
\hline $\begin{array}{l}\text { 7. External leakage test. } \\
\text { 8. Travelling length detection. }\end{array}$ & $\begin{array}{l}\text { To oil leakage on piston rod seals, cylinder head welding, cylinder } \\
\text { The stroke length is } 758 \mathrm{~mm} .\end{array}$ & Qualified \\
\hline
\end{tabular}

\section{Summary}

In this study, we finished the quality-detection of boom cylinder for remanufactured products on ZL 50C wheel loader. The methods and standards of quality-detection of boom cylinder for remanufactured products are proposed. Experimental results and practical implications show that methods and standards we made are feasible on quality-detection, which will ensure remanufactured products to perform similarly to a new one, with the same quality.

Like all research efforts, this study is not without limitations. The standards of our study might be limited by the repaired technology used. Only a repaired technology is used for boom cylinder repairing. With the development of Chinese characteristic surface technology, more technology can be used for the returned parts.

Despite these limitations, our study suggests important results for researchers and enterprises, methods and standards of quality-detection of boom cylinder for remanufactured products are correct. The 
research also shows that customers will be willing to buy remanufactured products if it is guaranteed qualified. The quality-detection is becoming the core of remanufacturing produce.

In the future, more research will be focused on difference of quality-detection standards for remanufactured products considering different repairing technologies and reassembling methods.

\section{Acknowledgment}

The research was supported by Guangxi Natural Science Found, Project 2015GXNSFAA139280 and Guangxi University Natural Science Found, Project XBZ140447.

\section{References}

[1]Thorn, B.K., Rogerson, P. Take it back, IIE Solutions, 34 (4) (2002) 34-40.

[2]Zhang, T., Chu, J., Wang, X., Liu, X., Cui, P. Development pattern and enhancing system of automotive components remanufacturing industry in China, Resources, Conservation, \& Recycling, 55 (6) 613-622.

[3]Cheng-Han $\mathrm{Wu}, \mathrm{OEM}$ product design in a price competition with remanufactured product, Omega ,vol.41,2013,pp.287-298.

[4]Benjamin T. Hazen, Robert E. Overstreet, L. Allison Jones-Farmer, Hubert S. Field. The role of ambiguity tolerance in consumer perception of remanufactured products Original Research Article, International Journal of Production Economics, 135(2)(2012):781-790.

[5]Liu Bing, Dong Shi-Yun , Xu Bing-Shi , He Peng .Investigations and Applications of UT in Evaluation of Coating Quality in Remanufacturing. Nondestructive Testing,2010, (03), 196-200.(in Chinese)

[6]Ana Paula Barquet, Henrique Rozenfeld ,Fernando A Forcellini. An integrated approach to remanufacturing: model of a remanufacturing system, Journal of Remanufacturing, (2013)3-1.

[7]Huang W, Yang J, Hong Q, et al. Remanufacturing and benefits analysis of construction machinery hydraulic valves, Journal of China Surface Engineering, 26(1),(2013) 77-79.(in Chinese)

[8]Geyer, R., Van Wassenhove, and L. N., \& Atasu, A. ,The economics of remanufacturing under limited component durability and finite life cycles on remanufacturing profit,Management Science, vol. 53(1), pp. 88-100.

[9]Guide Jr, and V. D. R. Jr, Production planning and control for remanufacturing: Industry practice and research needs, Journal of Operations Management, vol.18(4) ,2000,pp.467-468

[10]Xu Bin-shi. Theory and technology of equipment remanufacture engineering. Beijing : National Defense Industry Press, 2007. (in Chinese)

[11]Serra Caner Bulmus, Stuart X. Zhu, and Ruud Teunter, Competition for cores in remanufacturing, European Journal of Operational Research, vol.233,2014,pp.105-113.

[12]Wei Huang.Honing remanufacturing and experimental study on properties of Hydraulic cylinder[ A].The Fourth Annual Conference of the National Local Mechanical Engineering Society[C].Ganshu ,China,(2014)76-80.

[13]Huang Da-ming, Jiang Dai-xiang, Li Yue-peng, et al. Technical feasibility analysis for remanufacturing technology method in hydraulic cylinder based on ANSYS , Journal of Guangxi University(Natural Science Edition), 5 (2013):1040-1046. (in Chinese) 